\title{
Barcelona Scoliosis Physical Therapy School - BSPTS - based on classical Schroth principles: short term effects on back asymmetry in idiopathic scoliosis
}

\author{
M Jelačić, M Villagrasa, E Pou, G Quera-Salvá, M Rigo
}

From 8th International Conference on Conservative Management of Spinal Deformities and SOSORT 2011

Annual Meeting

Barcelona, Spain. 19-21 May 2011

\section{Background}

Previous results have shown the specificity of Schroth exercises (according to BSPTS protocol) but in a series including patients under bracing [1-4].

\section{Objective}

To investigate the short term effects of an intensive program of exercises on back asymmetry in idiopathic scoliosis with no other treatment.

\section{Materials and methods}

Retrospective, including 47 patients with IS treated exclusively with exercises. Mean age $18.64 \pm 5.78$ years. Outpatient Intensive Rehabilitation was carried out, three hours a day, five days a week, 4 weeks. Surface topography (Formetric) was performed to measure trunk imbalance, surface rotation and lateral deviation before and after the treatment period. The obtained pre- and posttreatment values were then compared.

\section{Results}

The mean trunk imbalance prior to and after the treatment was $10.16 \mathrm{~mm}$ and $8.53 \mathrm{~mm}$ respectively $(\mathrm{p}<0.05)$. The pre-treatment mean value of the lateral deviation (rms) was $13.92 \mathrm{~mm}$, compared to the post-treatment one of $11.96 \mathrm{~mm}(\mathrm{p}<0.05)$ and of the lateral deviation $(\max )$ was $25.6 \mathrm{~mm}$ and $21.42 \mathrm{~mm}$ respectively $(\mathrm{p}<0.05)$. The mean initial value of the surface rotation ( $\mathrm{rms}$ ) was 6.88 degrees, reaching 6.52 degrees at the end of the treatment $(\mathrm{p}<0.05)$ and of the surface rotation $(\max )$ 13.22 degrees and 11.88 degrees respectively $(\mathrm{p}<0.05)$.

\section{Conclusions}

Current results suggest that exercises according to Schroth principles, following BSPTS protocol, are able to improve back asymmetry, spinal imbalance in the frontal plane and virtual spinal geometry in a short term, confirming specificity in its mechanics of action.

Published: 27 January 2012

\section{References}

1. Rigo M, Quera G, Puigdevall N, Corbella C, Gil MJ, Martinez S, Villagrasa M: Biomechanics of specific exercises to correct scoliosis in 3D[abstract]. Pediatr Rehabil 2004, 7:53-4.

2. Freidel K, Petermann F, Reichel D, Warschburger P, Weiss HR: Medical and psychosocial outcome of Scoliosis In-Patient Rehabilitation (SIR). 5th international conference on conservative management of spinal deformities Athens; 2008.

3. Weiss HR, Steiner A, Reichel D, Petermann F, Warschburger P, Freidel K: Medizinischer Outcome nach stationärer Intensivrehabilitation bei Skoliose. Phys Med Rehab Kuror 2001, 11:100-103.

4. Lehnert-Schroth C: Dreidimensionale Skoliosebehandlung. Urban/Fischer, München; 62000.

\section{doi:10.1186/1748-7161-7-S1-O57}

Cite this article as: Jelačić et al:: Barcelona Scoliosis Physical Therapy School - BSPTS - based on classical Schroth principles: short term effects on back asymmetry in idiopathic scoliosis. Scoliosis 2012 7(Suppl 1):057. 